\title{
APLICACIÓN DE TÉCNICAS SIG PARA LA COBERTURA SUPERFICIAL Y DISTRIBUCIÓN DEL BOSQUE DE Polylepis EN LAZONAANDINA DE MOQUEGUA2018
}

\author{
APPLICATION OF GIS TECHNIQUES FOR SUPERFICIAL COVERAGE AND \\ DISTRIBUTION OF THE Polylepis FOREST IN THE ANDEAN AREA OF \\ MOQUEGUA2018
}

\author{
${ }^{1}$ Maribel Pacheco Centeno \\ ${ }^{2}$ Pablo Franco León \\ ${ }^{3}$ Cesar Cáceres Musaja \\ ${ }^{4}$ Marco Navarro Guzman \\ ${ }^{5}$ Cesar Jove Chipana
}

\section{RESUMEN}

En el presente trabajo presentamos los resultados del análisis especializado en Sistemas de Información Geográfica (SIG) de los bosques relictos alto andinos de Polylepis, existentes en la región Moquegua. Dicho análisis ha permitido determinar una cartografía más detallada y actualizada respecto de las que estudios anteriores, realizados en la misma zona, habían propuesto. A través de la aplicación de técnicas combinadas de modelamiento de distribuciones potenciales de especies (MDE), algoritmos probabilísticos (Bioclim y Domain), la interpretación visual de imágenes satelitales (Mejía, 2014) y la comprobación de campo se logró determinar en toda la zona andina de la región Moquegua una superficie actualizada de 23081,60856 ha de bosques de Polylepis. Este resultado fue comparado con las estimaciones realizadas por el MINAM (2015), en la memoria descriptiva del Mapa Nacional de Cobertura Vegetal, donde se estima para la zona una extensión de 5265,343 ha. La información obtenida a partir de nuestra investigación, muestra datos mucho más precisos acerca de la superficie y distribución actual de los relictos en el lugar objeto de estudio; por ende, pueden servir como herramienta y guía en la cartografía a fin de cuantificar relictos aún existentes en otros espacios, así como para el manejo sostenible de los ecosistemas que se desarrollen en ellos.

Palabras claves: Polylepis, relictos, SIG.

\section{ABSTRACT}

In the present work we present the results of the specialized analysis in Geographic Information Systems of the High Andean Forests of Polylepis of the Moquegua Region. This analysis has made it possible to determine a more detailed and updated cartography with respect to those that previous studies, carried out in the same area, had proposed. Through the application of combined techniques of modeling of potential species distributions (MDE), probabilistic algorithms (Bioclim and Domain), visual interpretation of satellite images (Mejía, 2014) and field verification, it was possible to determine in all the Andean area of the Moquegua region an updated area of 23 081.60856 ha of Polylepis forests. This result was compared with the estimates made by MINAM (2015), in the descriptive report of the National Map of Vegetable Coverage, where an extension of 5 265,343 ha is estimated for the area.The information obtained from our research shows much more precise data about the surface and current distribution of the relicts in the place under study; therefore, they can serve as a tool and guide in the cartography in order to quantify relicts still existing in other spaces, as well as for the sustainable management of the ecosystems that develop in them.

Keywords: Polylepis, relic, SIG.

\footnotetext{
Universidad Nacional de Moquegua. Moquegua-Perú. E-mail: maribel.pacheco@hotmail.com

${ }^{2}$ Universidad Nacional Jorge Basadre Grohmann. Tacna-Perú. E-mail: pablofranco2@hotmail.com

${ }^{3}$ Universidad Latinoamericana CIMA. Tacna-Perú.

${ }^{4}$ Universidad Latinoamericana CIMA. Tacna-Perú.

${ }^{5}$ Universidad Nacional Jorge Basadre Grohmann. Tacna-Perú.
} 


\section{INTRODUCCIÓN}

A pesar del desarrollo actual de la humanidad y su acelerado proceso de modernización, el ser humano ha conservado una poderosa atracción hacia los bosques, puesto que son vistos como proveedores de una infinidad de servicios asociados a nuestro bienestar. Asimismo, estos siempre han despertado el interés de los investigadores y en los últimos años son los bosques de montaña, los andinos especialmente, los que concentran mayormente su atención (Doroujani, 2008).

El género Polylepis (Rosaceae) incluye aproximadamente 27 especies (Mendoza y Cano, 2011; Kessler y Schmidt-Lebuhn, 2006), que forman bosques de hoja perenne con poblaciones muy fragmentadas a lo largo de las alturas de los Andes tropicales y subtropicales (Zutta et al., 2012).

Existen en el país estudios promovidos por diversas instituciones académicas como las universidades, así también por algunos investigadores independientes, acerca de la forma en que se distribuye el género Polylepis, su estado de conservación, su composición florística, entre otros. Sin embargo, aún no se tiene datos precisos de la superficie total, distribución y ubicación de este tipo de bosques. De allí, la importancia de continuar desarrollando investigaciones sobre este tema, en base a perspectivas metodológicas más avanzadas y actuales.

Si bien es cierto que ya se utilizaron anteriormente imágenes de satélite de media a baja resolución, a fin de realizar seguimientos del cambio en el tiempo o extensión del hábitat forestal o de la calidad del mismo (Braun, 1997), este tipo de imágenes resulta inadecuado para detectar los hábitats que son difíciles de identificar, como sucede por ejemplo con los pequeños en extensión o distribución irregular (Matos et al., 1992; Benham et al., 2011).

Las imágenes tomadas durante la última década por el satélite Quick-Bird de Digital-Globe y SPOT de 2,5 m de resolución, hoy en día están disponibles de forma gratuita en la interface de Google Earth (Potere, 2008). Dichas imágenes proporcionan ahora un recurso sin precedentes para la conservación, manejo y estudio en diversas ramas como las ciencias forestales, lo cual permite la gratuidad de cuantificación y georreferenciación de los hábitats más amenazados (Benham et al., 2011).

El presente trabajo tiene por objetivo ofrecer una guía metodológica que amplíe los conocimientos de los relictos de bosques en la zona andina del departamento de Moquegua, a través del análisis combinado de modelos de distribución de especies probabilísticos y del análisis digital en imágenes satelitales; los cuales están disponibles gratuitamente en diferentes fuentes virtuales, entre ellas Google Earth.

\section{MATERIAL Y MÉTODOS}

\section{ÁMBITO DE ESTUDIO}

La investigación se desarrolló en toda la superficie andina de la región de Moquegua, en donde se incluyen las provincias de Mariscal Nieto y Sánchez Cerro. (Figura 1).

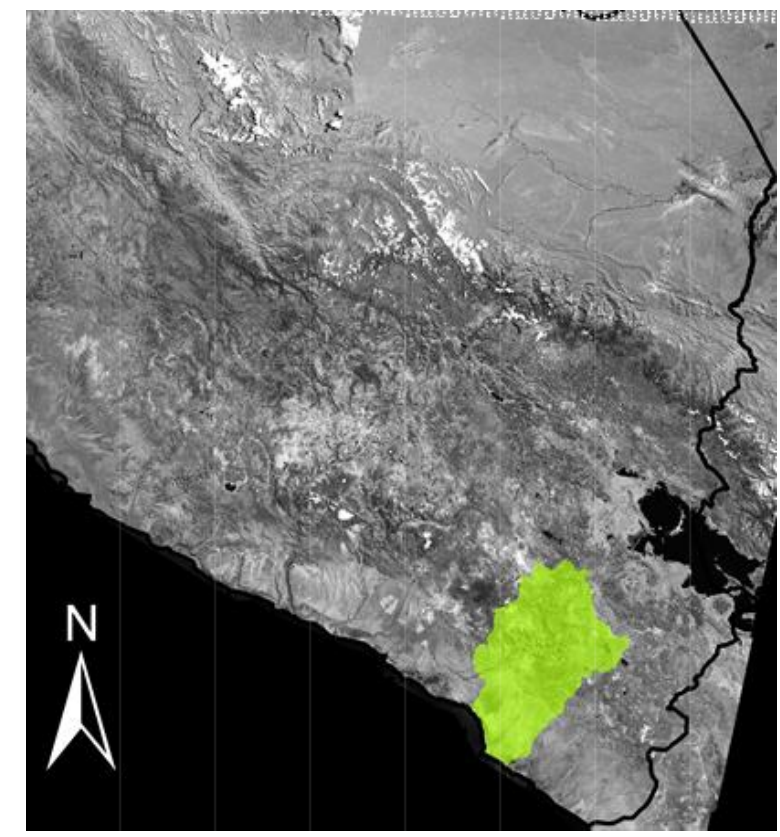

Figura 1. Mapa del ámbito de estudio - Región Moquegua

El estudio permitió analizar imágenes LANDSAT 7, para Perú en el periodo 2010 - 2017 (resolución $30 \mathrm{~m}$ ), Modelos de Elevación ASTER-GDEM, para el Perú (resolución $30 \mathrm{~m}$ ), Hojas de la Carta Nacional IGN a escala $1 / 100000$ en formato digital y base de datos del Worldclim (http://www.worldclim.org/) (resolución 1 $\mathrm{km})$.

El modelo conceptual para el desarrollo del presente estudio está basado en 8 etapas (Figura 2):

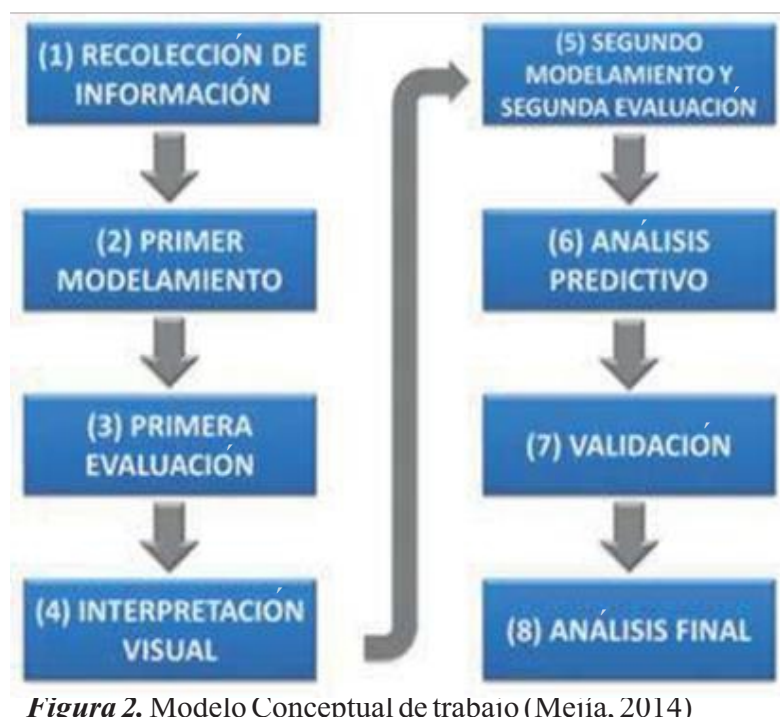

\section{Métodos de Modelado (algoritmos y aplicativos informáticos)}

Para la creación de los diferentes modelos de distribución de especies (MDE), se utilizaron los algoritmos BIOCLIM y DOMAIN. Cada uno fue ejecutado en su propia interface (aplicativo informático). Se realizaron $5 \mathrm{MDE}$ a partir de 
combinaciones entre los conjuntos de variables (o bases de datos), los puntos "train" y los algoritmos definidos.

El software utilizado fue ARC GIS 10.3, debido a que contiene el algoritmo BIOCLIM, el cual fue obtenido y descargado de Internet (http://www.diva-gis.org/) por ser de libre acceso. En esta interface se pudieron generar los archivos raster de los MDE planteados.

Una vez efectuado el análisis predictivo en aquellas zonas detectadas sin cobertura de imágenes de alta resolución en Google Earth y superiores a la cota guía de $3500 \mathrm{~m}$, se las superpuso con la nueva área base del MDE "Segunda Aproximación"; para realizar, posteriormente, la digitalización de los relictos mediante interpretación visual de estas nuevas imágenes.

Al igual que la interpretación visual, el área base denominada "Segunda Aproximación" pasó a utilizarse como entrenamiento para conocer el color, tono y textura específicos de los bosques en las nuevas figuras. Toda esta información fue complementada con los resultados de una comparación entre imágenes de diferentes resoluciones.

\section{RESULTADOS}

\section{Interpretación Visual}

Se digitalizó 104 relictos de bosques, con una extensión total de 23081,60858 ha, correspondientes a la zona andina de la región Moquegua.

La caracterización preliminar y general del paisaje, permitió identificar los elementos que existen en la zona de estudio. Con mayor frecuencia, se pudo visibilizar fragmentos pequeños. En su mayoría, los parches están regularmente conectados entre sí por medio de quebradas. Sin embargo, también se observó que pequeños relictos más aislados tienen poca conectividad y están separados por espacios abiertos de pajonales.

Los bosques de Polylepis dentro de las imágenes satelitales de alta resolución presentaron como característica general, la presencia de copas de árboles semejantes a objetos hinchados de color verde, con sombras diferentes, además de parches contiguos de árboles que denotaban ser más oscuros, más ásperos en textura, y con mayor verdor que el color de fondo de los alrededores de los mismos bosques (Figura 3 ).

La mayoría de los fragmentos digitalizados presentan bordes alongados, según el método de Forman (1995). Pudo percibirse, asimismo, que cada fragmento constituido por parches muy pequeños revelaba diferentes estados de degradación (Figura 4).

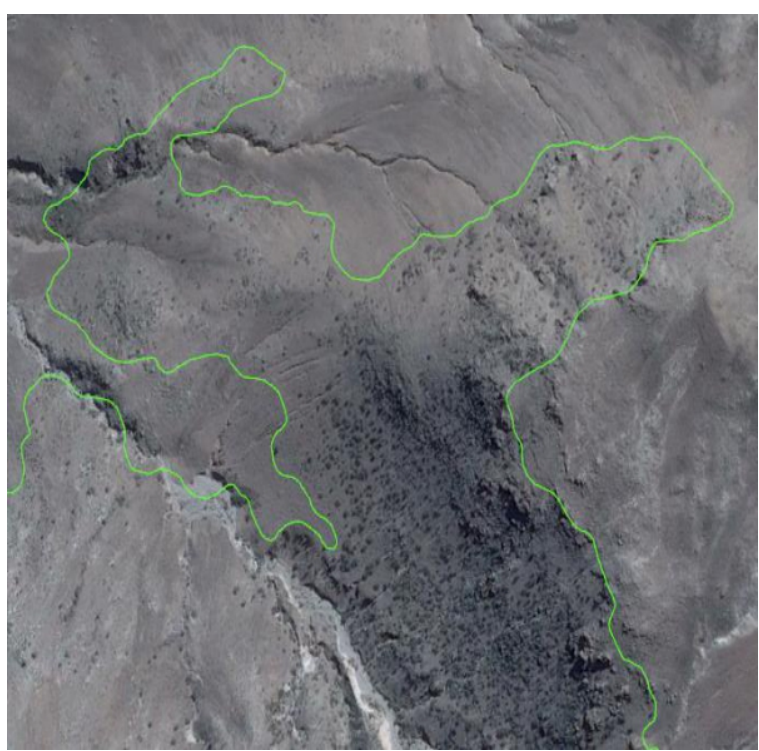

Figura 3. Características generales en texturas de los bosques de Polylepis

Fuente: Interface Google Earth

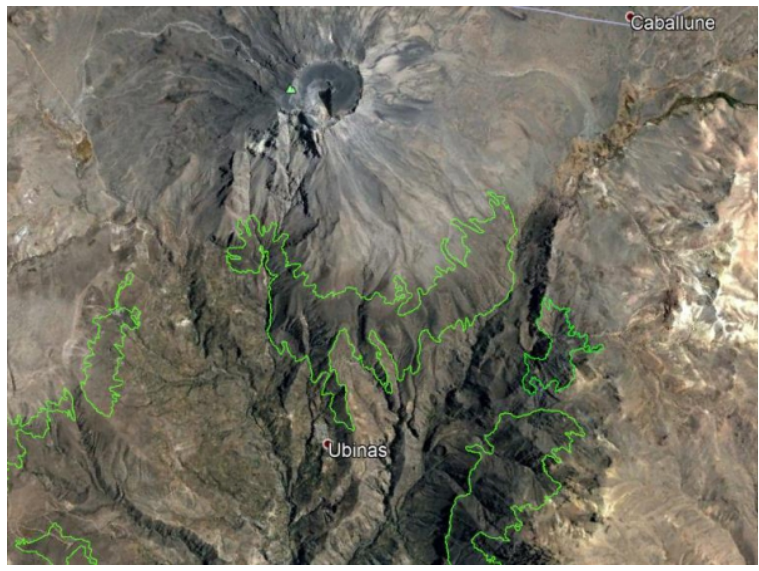

Figura 4. Características generales de la forma de los bosques de Polylepis

Fuente: Interface Google Earth

El área base proveniente de la primera aproximación, donde fueron encontrados mayormente los bosques, resultó menos extensa (Figura 5), tomando como referencia el límite teórico de la distribución (Alturas superiores a $3500 \mathrm{~m}$ ). En este nuevo contexto el área a trabajar se redujo considerablemente de $70 \%$ a $30 \%$ del total del territorio. 


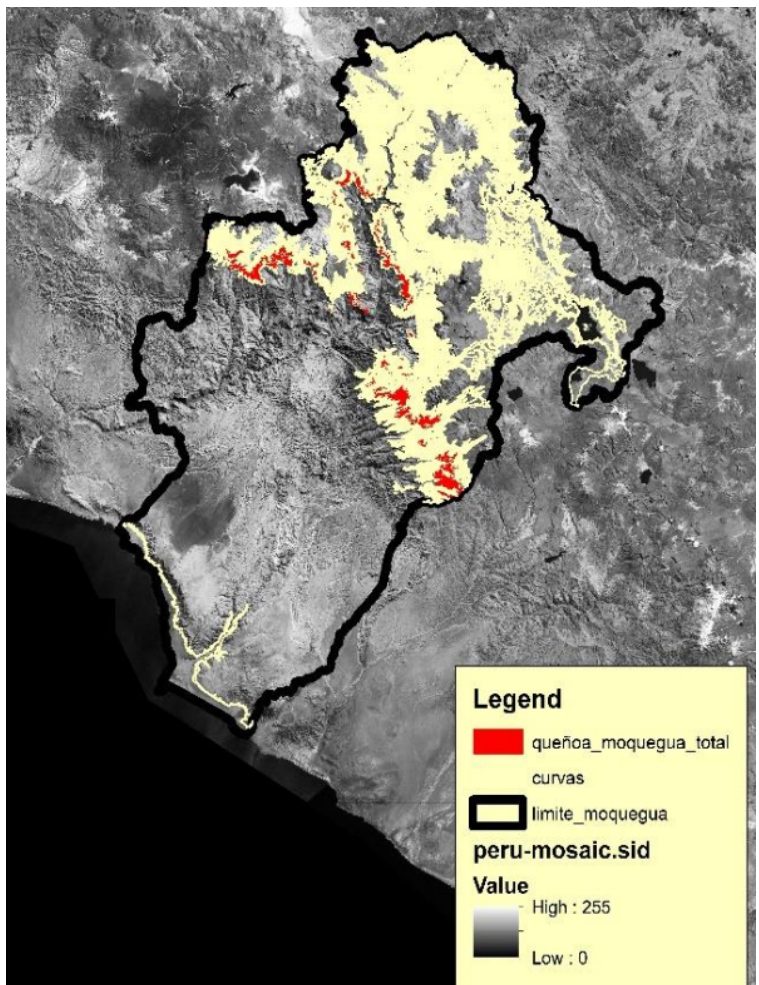

Figura 5. El área de entrenamiento es menos extensa que el total del territorio

Identificar con precisión las características más significativas y resaltantes en los bosques de Polylepis, que nos permitiese interpretar y diferenciar esta clase de bosques en comparación con otro tipo de unidades en imágenes de menor resolución (mayor tamaño de píxel), fue relativamente complicado; puesto que no existe un patrón definido en cuanto a la textura, el tono y el color exclusivos para este tipo de ecosistemas (Figura 6).

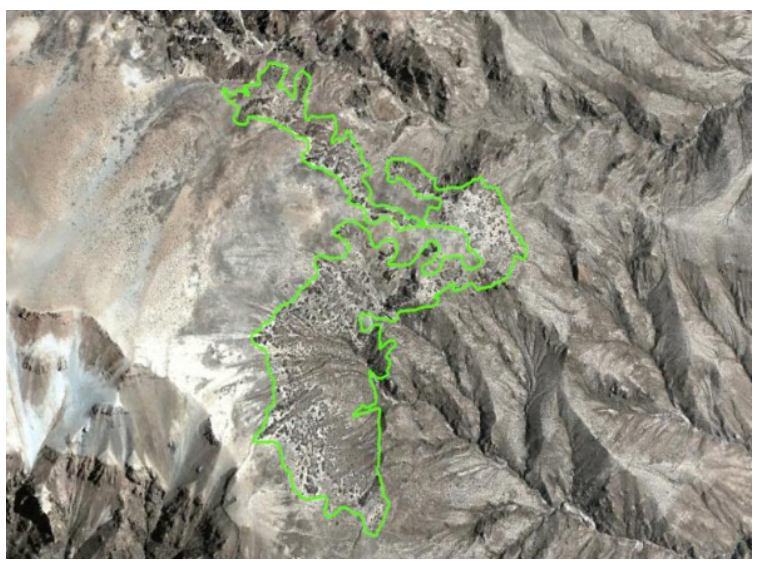

Figura 6. Texturas de Bosques en Imágenes CBERS

Fuente: Interface Google Earth

Este fue uno de los principales problemas por los que estudios anteriores no pudieron digitalizar dichos bosques con altos grados de precisión, sobre todo cuando utilizaron imágenes Landsat (Figura 7), debiendo recurrir a métodos como la clasificación supervisada y la no supervisada, tal como refieren Benham et al. (2011).

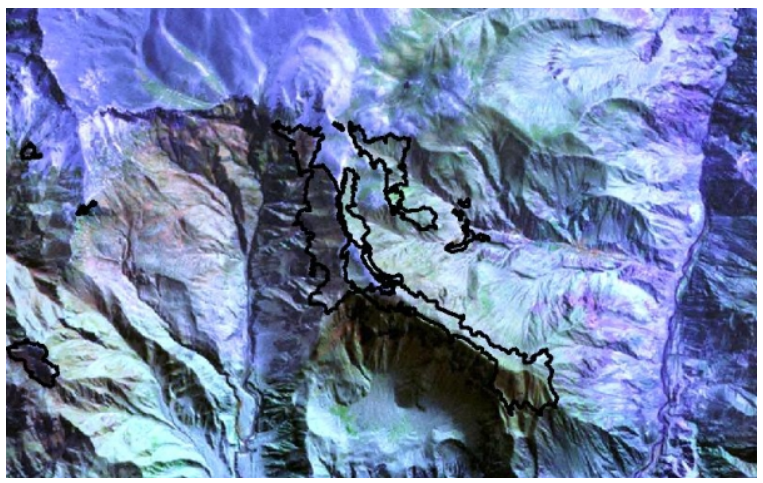

Figura 7. Bosque de Polylepis

Fuente: Imagen satelital Landsat 7-TM (30 m)

Resulta claro que para este tipo de investigación se debe poner el mayor esfuerzo en la obtención de los registros, buscando una mayor representatividad de la muestra-especie a través de un análisis adecuado de la información obtenida para evitar los sesgos y así obtener resultados reales (Hirzel y Guisan, 2002). En base a este criterio, se optó en la etapa del primer modelamiento, por recurrir a los registros de bosques de Polylepis obtenidos mediante una revisión bibliográfica; no obstante, estos fueron relativamente muy escasos (24 puntos) en comparación de la totalidad de parches encontrados durante la etapa de interpretación visual: 104 relictos de diferentes tamaños y, por tanto, de diferente representatividad.

Si bien los registros iniciales provienen de diferentes fuentes reconocidas, es posible suponer que pueden contener un cierto sesgo a la hora que fueron levantados; tomemos como ejemplo un bosque de Polylepis donde, comúnmente, no se registra la coordenada central del parche evaluado, solo de los flancos y/o contornos, debido a la dificultad que presenta ya sea por acceso o tiempo (Yallico, 1992). Otro factor que podría incrementar el sesgo, es que no existe una representatividad homogénea por tamaño de bosque, muchas veces se toma como registro un relicto tal como si fuera un bosque de grandes extensiones.

\section{BOSQUES DE QUEÑOALES SEGÚN EL MAPA DE COBERTURA VEGETAL DEL PERÚ}

El Perú es uno de los países con mayor diversidad de ecosistemas del mundo, los cuales se caracterizan por su gran complejidad vegetal, climática, geomorfológica y edáfica. La flora y vegetación se encuentran representadas por una variedad de formas de vida vegetal o formas de crecimiento, distribuidas en paisajes que van desde las llanuras desérticas y semidesérticas, así como las llanuras aluviales con bosques lluviosos, hasta los paisajes colinosos y montañosos. El Ministerio del Ambiente (MINAM) es el encargado de conducir el proceso de inventario y evaluación del patrimonio natural; $\mathrm{y}$, como tal, ha 
elaborado el Mapa Nacional de Cobertura Vegetal (2015), el cual constituye una herramienta de gestión de los recursos naturales y de los servicios ecosistémicos, en el marco de la política nacional del ambiente. El Mapa Nacional de Cobertura Vegetal está conformado por unidades espaciales definidas y clasificadas en base a criterios geográficos, fisonómicos, condición de humedad y excepcionalmente florísticos. La memoria descriptiva del mapa muestra la distribución geográfica, superficie y características biofísicas generales de los diversos tipos de cobertura vegetal que cubren el país, entre ellos el bosque relicto alto andino Polylepis con una superficie para la región de Moquegua de 5 265,343 ha (Figura 8).

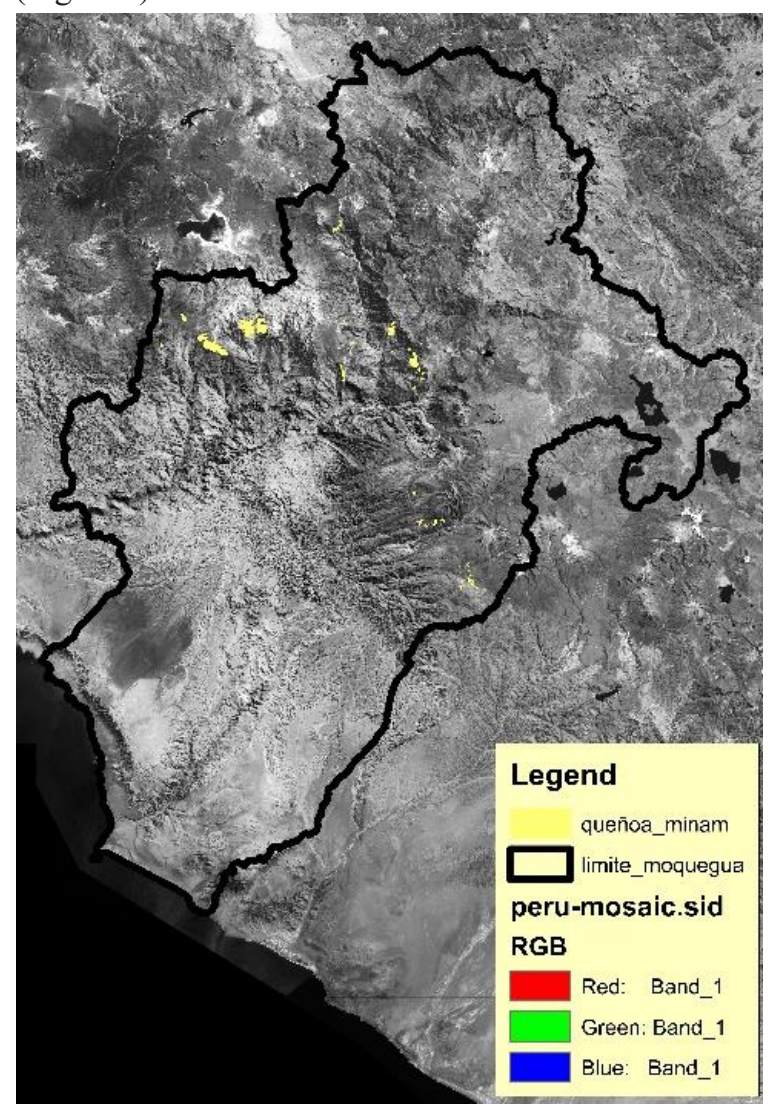

Figura 8. Bosque relicto alto andino según Mapa de Cobertura Vegetal del Perú

Fuente: MINAM (2015)

\section{BOSQUES O RELICTOS DE QUEÑOALES DE LAREGIÓN DE MOQUEGUA}

Después del análisis final de la realización de modelos con la integración de variables, se llegó a determinar la superficie total de los bosques en 23081,60858 hectáreas (Figura 9).

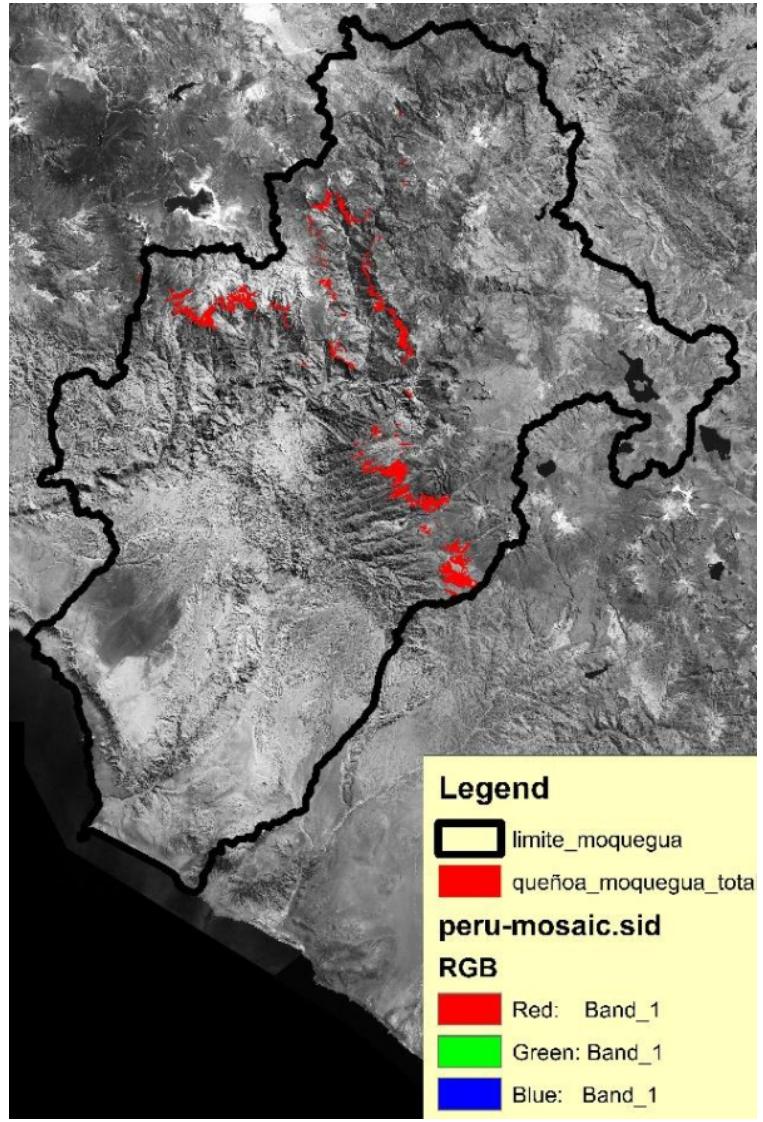

Figura 9. Distribución de bosques de Polylepis en el departamento de Moquegua 2018

Fuente: Proyecto POLYLEPIS 2018

\section{DISCUSIÓN}

Debido a la situación crítica de los bosques en la zona andina de Moquegua es necesario que para su conservación se documente el estado actual, la distribución y la extensión de los bosques naturales de la forma más precisa posible. Solamente en base a parámetros reales se puede diseñar e implementar a futuro una adecuada gestión, con el fin de conservar realmente estas coberturas.

Una de las limitaciones que se presenta en estudios de este tipo son las técnicas que actualmente más se utilizan en estudios cartográficos, involucrando métodos de clasificación supervisada y no supervisada de imágenes Landsat y Aster (Benham et al., 2011; Dourojeanni, 2008; Braun, 1997); en los cuales resulta difícil clasificar y/o diferenciar los parches más pequeños (los que abundan en la actualidad), y por tanto no se logra una mayor precisión. Por esta razón, en este estudio, no se realizó una comparación metodológica para determinar dichas diferencias.

Cabe resaltar que estos métodos, por su relativa facilidad en términos de tiempo, dejan de lado la interpretación visual cuyos resultados implican mayores esfuerzos y, sin embargo, son altamente precisos, tal como lo demostró Malleux (2003) cuando comparó diferentes metodologías en imágenes 
satelitales en un bosque amazónico; el cual ofrece mayores dificultades en su interpretación, por no desmerecer la menor biodiversidad del género Polylepis, pero sí debe reconocerse la relativa homogeneidad en la cobertura de sus bosques.

Es importante destacar que se logró determinar un total de 104 nuevos relictos, ubicados en la parte suroeste de Moquegua, en su mayoría polígonos entre pequeños y medianos a grandes; los pequeños fueron difíciles de digitalizar, por cuanto se estima que fueron relegadas áreas difíciles de detectar.

Otra de las limitaciones de esta investigación fue determinar con precisión las características más resaltantes en los bosques de Polylepis — como ya se señaló antes-, las cuales son necesarias para interpretar y diferenciar estos bosques en comparación con otro tipo de unidades en imágenes de menor resolución, ya que no existe un patrón definido en lo que se refiere a su textura, su tono y su color exclusivos. En el Mapa de Cobertura Vegetal del Perú, elaborado por el Ministerio del Ambiente, aparece información sobre la superficie, características generales y distribución geográfica de los diferentes tipos de cobertura vegetal existente en el país. Dicho mapa fue elaborado en base a imágenes satelitales del año 2015 , con escala de interpretación de 1:100 000. No obstante, señala una superficie del bosque relicto alto andino Polylepis en la región de Moquegua de 5 265,343 ha, dato que no es correcto.

\section{CONCLUSIONES}

Se consiguió poner en práctica una propuesta metodológica para la Cartografía de Bosques del género Polylepis, a través del uso de técnicas combinadas de modelamiento de distribuciones potenciales de especies, algoritmos probabilísticos y la interpretación visual de imágenes satelitales de diferentes fuentes, entre ellas Google Earth. Lo que permitió determinar la superficie de los bosques de Polylepis de la región de Moquegua. Estos valores obtenidos permiten conocer mejor la realidad, así como confrontar las estimaciones realizadas a partir de investigaciones anteriores en estos mismos bosques.

La conclusión más relevante a la cual llegamos es la estimación precisa de la superficie de los bosques del género Polylepis en la zona andina de Moquegua, cuya extensión en base a relictos abarca 23 081,60858 ha; el $100 \%$ de esta información fue trabajada mediante la interpretación visual.

Nuestros resultados difieren con las estimaciones propuestas por el MINAM (2015) en su Mapa de Cobertura Vegetal, el cual estima 5265,343 ha de Polylepis en la zona objeto de estudio. La presente investigación ha permitido determinar el incremento en 17816,27 ha de cubierta vegetal de los bosques relictos alto andino para la región de Moquegua. Hecho que demuestra la relevancia de este trabajo y señala su proyección en nuevos estudios que permitan la aplicación del análisis combinado de modelos de distribución de especies probabilísticos y del análisis digital en imágenes satelitales, a fin de ampliar los conocimientos de relictos de bosques de distintos géneros en otras zonas del país.

\section{Agradecimiento:}

Agradecemos a la Universidad Nacional de Moquegua por el financiamiento canon del proyecto: ESTUDIO DE LOS BOSQUES DE POLYLEPIS RELICTOS ALTOANDINOS PARA LA GESTIÓN SOSTENIBLE EN LA MITIGACIÓN DE LOS EFECTOS DEL CAMBIO CLIMÁTICO DE LA REGIÓN MOQUEGUA, lo que ha facilitado la realización del presente estudio.

\section{REFERENCIAS BIBLIOGRÁFICAS}

Alcocer R., Servat G., Mendoza W. (2002). Extension of the distribution of the migratory range of the "Black-fronted Ground Tyrant" Muscisaxicola frontalis (Aves: Tyrannidae) in Perú. Revista Peruana de Biología. 18: 381-382.

Anderson, R., Lew, D. \& Peterson, A. (2003). Evaluating predictive models of species distributions: criteria for selecting optimal models, Ecological Modelling. 162, pp. 211232.

AUTOCOLCA (Autoridad del Colca y Anexos, PE). (2006). Plan Maestro para el desarrollo y gestión sostenible del turismo en el valle del Colca, la Reserva Nacional de Salinas y Aguada Blanca y el Baltaxe, R. 1980. The Application of LANDSAT Data to tropical forest surveys. Swedish Funds-in-trust. FOR: TF/INT/333(SUE): FAO 122p.

Benito, B., Peñas, J. (2007). Aplicación de modelos de distribución de especies a la conservación de la biodiversidad en el sureste de la Península Ibérica, Geofocus, 7, pp. 100 - 119.

Braun, G. (1997). The use of digital methods in assessing forest patterns in an andean environment: The polylepis example. Mountain Research and Development, 17(3), pp. 253-262.

Budowski, G. (1985). La conservación como instrumento para el desarrollo, San José, C. R., Editorial de la Universidad Estatal a Distancia. 398 p.

Busby, J. (1991). "BIOCLIM - a bioclimate analysis and prediction system", en Margules, C.R., y Austin, M.P., (Eds.), Nature conservation: cost effective biological surveys and data analysis. CSIRO, pp. 64-68.

Carpenter, G., Gillson, A. \& Winter, J. (1993). "DOMAIN: a flexible modeling procedure for mapping potential distributions of plants 
and animals", Biodiversity and Conservation, 2, pp. 667-680.

Campbell, J.(1996). Introduction to Remote Sensing. 2a. ed. Virgina Polytechnis Institut and State University, The Guilford Press, Nueva York, USA. 551 p.

Chang, J. (2002). Forest Fragmentation Analyisis using GIS and Remote Sensing Techniques: The Polylepis Forest Case in the Peruvian High Andes. Forestry and Forest Products Research Institute. Tokyo, Japan: 27 p.

CONAM (Consejo Nacional del Ambiente, PE) (2007). Plan Regional Sur de lucha contra la desertificación y sequía. Secretaría Técnica del Consejo directivo de Arsuldes. Arequipa, Perú. $79 \mathrm{p}$.

Dourojeanni, P. (2008). Distribución y conectividad de bosques alto andinos (Polylepis) en la cuenca alta del río Pativilca. Tesis (Ing. Geógrafo). Universidad Católica del Perú. Lima, PE. $82 \mathrm{p}$.

Engler, R., Guisan, A. \& Rechsteiner, L. (2004). “An improved approach for predicting the distribution of rare an endangered species from occurrence and pseudo-absence data", Journal of Applied Ecology, 41,pp. 263-274.

Ferrier, S., Guisan, A. (2006). "Spatial modelling of biodiversity at the community level", Journal of Applied Ecology, 43, pp. 393-404.

Fjeldsa, J., Kessler, M. (1996). Conserving the biological diversity of Polylepis forests of the highlands of Perú and Bolivia. Copenhagen: Nordic Foundation for Development and Ecology (NORDECO). 214p.

Fielding, A., Bell, J.(1997). "A review of methods for the assessment of prediction errors in conservation presence/ absence models", Environmental Conservation, 24, pp. 38-4

Fjeldsa, J. (1987). Birds of relict forest in the high Andes of Perú and Bolivia. Zoological Museum/University of Copenhagen, Dinamarca. $80 \mathrm{p}$.

FONAM (Fondo Nacional del Ambiente, PE), (2006). Propuesta Final para una definición peruana de bosques a ser utilizada en proyectos de uso de la tierra, cambio de uso y silvicultura bajo el protocolo de Kyoto durante el primer periodo de compromiso. Lima Perú. 3 p.

García, M. (2008). Modelos Predictivos de Riqueza de Diversidad vegetal - Comparación y Optimización de métodos de modelado ecológico. Memoria de Tesis Doctoral. Universidad Complutense de Madrid Facultad de Ciencias Biológicas. 188 p.

Graham, C; Moritz, C. \& Williams, S. (2006). "Habitat history improves prediction of biodiversity in a rainforest fauna", Proceedings of the Natural Academy of Science of USA. 103, pp. 632-636.

Hirzel, A. \& Guisan, A. (2002). "Which is the optimal sampling strategy for habitat suitability modelling”, Ecological Modelling, 157, pp. $331-341$.

Hurtado, C.(2007). Uso de modelos de predicción como herramienta para estimar el área de distribución potencial de la especie aniba perutilis hemsley (Comino Crespo) en el departamento del valle del Cauca. Tesis (Ecólogo). Popayan, VE: Fundación Universitaria Popayán. 72p.

IGN-MINEDU. Carta nacional digital, Esc. $1: 100,000$. IGN (Instituto Nacional Geográfico)

MINAM. (2015). Mapa Nacional de Cobertura Vegetal Memoria descriptiva del Perú. Ministerio del Ambiente. Lima-Perú.

Mejía, A. (2014). Tesis Metodología para la cartografía de bosques del género Polylepis, aplicando Geomática. Universidad Nacional Agraria La Molina Facultad de Ciencias Forestales. Lima- Perú.

INRENA (Instituto Nacional de Recursos Naturales, Ministerio de Agricultura). (1995). Guía explicativa del mapa forestal. INR-49-DGF, Lima, Perú. 147 p.

Kessler, M., Schmidt-Lebuhn A. (2006). Taxonomical and distributional notes on Polylepis (Rosaceae). Organisms, Diversity \& Evolution 6, pp. 67-69. 